\title{
Effect of Household Denture Cleansers on Color Stability and Tensile Bond Strength of Two Different Heat Polymerized Acrylic Resins
}

\author{
${ }^{1}$ Anupama Suresh Patankar, ${ }^{2}$ Roseline Meshramkar, ${ }^{3}$ Ramesh Nadiger, ${ }^{4}$ Paulami Bagchi
}

\begin{abstract}
Aim: Denture cleansers are used not only to clean dentures but also for disinfection of dentures. Among household denture cleansers, bleach (which contains sodium hypochlorite) and vinegar (which contains acetic acid) have been found to be powerful disinfecting agents. The objectives of this in vitro study were to evaluate and compare the color stability and tensile bond strength of Trevalon and Lucitone 199 heat-cured resins after immersing in household denture cleansers like $1 \%$ household bleach and $50 \%$ vinegar.
\end{abstract}

Methodology: A total of 48 Trevalon and Lucitone 199 heatcure resin samples respectively were fabricated. The samples were divided into three groups of 16 samples each. They were immersed in $1 \%$ bleach, $50 \%$ vinegar and water (control) respectively. The samples were alternatively immersed in cleanser and water for 8 hours for 20 days simulating 30 days of use. At the end of 20 days, color stability and tensile strength were assessed with the help of spectro-guide and Instron universal testing machine respectively.

Results: Sodium hypochlorite and vinegar affected the color stability of Lucitone 199 heat-cure acrylic resin. The color of Trevalon heat-cure resin remained unaltered after immersion in both the cleansers. The change in tensile strength of both the resins was not significant after immersion in both the cleansers as compared with water which was used as control group.

Conclusion: This study concludes that for disinfection and cleansing of denture, sodium hypochlorite can be considered as long as the acrylic used is cross linked.

Keywords: Color stability, Denture base resin, Denture cleanser, Sodium hypochlorite, Tensile strength, Vinegar.

How to cite this article: Patankar AS, Meshramkar R, Nadiger R, Bagchi P. Effect of Household Denture Cleansers on Color Stability and Tensile Bond Strength of Two Different Heat

\footnotetext{
${ }^{1}$ Assistant Professor, ${ }^{2,3}$ Professor

${ }^{4}$ Associate Professor (Reader)

${ }^{1}$ Department of Prosthodontics, Sinhgad Dental College, Pune Maharashtra, India

2,3 Department of Prosthodontics, SDM Dental College, Dharwad Karnataka, India

${ }^{4}$ Department of Prosthodontics, DY Patil Dental School, Pune Maharashtra, India

Corresponding Author: Anupama Suresh Patankar, Assistant Professor, Department of Prosthodontics, Sinhgad Dental College, Pune, Maharashtra, India, Phone: 02025455505, e-mail: drpatankar02@yahoo.in
}

Polymerized Acrylic Resins. Int J Prosthodont Restor Dent 2015;5(4):95-100.

Source of support: Nil

Conflict of interest: None

\section{INTRODUCTION}

Complete dentures are fabricated using acrylic resin because of its low cost and relative ease of manipulation. There are several types of denture base acrylic resins; heat-polymerized acrylic resin, auto polymerized acrylic resin, and visible-light polymerized acrylic resin are often used for prosthetic purposes. ${ }^{1}$ Cleaning of dentures is not only essential for maintaining esthetics but also for maintaining hygiene. Denture cleansing is an important measure that can prevent cross-contamination and contributes to patient's oral health, denture longevity and overall quality of life. Denture cleansers are widely used to prevent denture plaque formation and colonization by Candida albicans and related Candida species which might lead to denture stomatitis. ${ }^{2}$ Commercial denture cleansers are classified into the following groups: neutral peroxides with enzymes, enzymes, acids, hypochlorites, peroxides, crude drugs, and mouth rinses for dentures. ${ }^{3,4}$

Sterilization and sanitization of dentures is not only important while using the dentures but also after polishing of dentures in the laboratory. It has been reported that dentures get inoculated by microorganisms while polishing the dentures using buff. ${ }^{5}$ This can be avoided by using denture cleansers to maintain hygiene of dentures. These denture cleansers work through mechanical or chemical action. An ideal denture cleanser should be simple to use, effectively remove organic and inorganic matter from denture surface, have bactericidal and fungicidal property and should be compatible with all denture base materials. They should be effective disinfecting agents. They should not cause any alteration in the structure of the prosthesis. ${ }^{6}$

Brushing is the most commonly used method for cleansing of dentures. Complete denture patients mostly belong to geriatric population. Since this activity requires motor coordination and physical fitness, elderly patients may not be able to carry it out efficiently. Hence, they 
prefer using chemical denture cleansers which require comparatively less effort for cleaning.

Many of the denture wearers in India belong to the lower socioeconomic group especially those opting for conventional complete dentures. These patients cannot afford commercial denture cleansers. In remote areas of India commercial denture cleansers are not available. Due to lack of education and information regarding the maintenance of dentures, some people are unaware of denture cleansers. In all such cases, patients prefer using products which are easily available on shelf in the house and are inexpensive for cleaning dentures.

One such commonly available household product is bleach. Chemically, it is sodium hypochlorite. It is used as a sanitizing agent and to remove stains from clothes and other surfaces. It is used in dentistry mainly for laboratory disinfection of acrylic prosthesis. Full strength sodium hypochlorite has shown to be powerful disinfectant. ${ }^{7}$ Vinegar is another household product used in cooking. It contains mainly acetic acid which acts as a disinfectant. ${ }^{8}$ It can be used either in concentrated form or diluted form for sanitization. These two products are commonly used as household denture cleansers. Color stability is an important factor of denture base resins. Color stability is a required characteristic of denture base resins, and it may provide important information on the serviceability of these materials.

Daily use of denture cleansers can affect the physical and mechanical properties of denture base materials. Many studies have been done to evaluate the effect of commercial denture cleansers on physical properties of acrylic resin. Out of these, a few studies have reported the effect of household denture cleansers on denture base acrylic resins. The findings of studies which have been done to evaluate the effect of sodium hypochlorite on color stability of acrylic resin have been contradictory. Some authors reported that there was no effect of sodium hypochlorite on color ${ }^{5,7,9}$ while some reported it did affect the color stability of acrylic resin. ${ }^{10}$

Hence, the aim of this study was to evaluate the effect of household denture cleansers like bleach and vinegar on color stability and tensile strength of two different types of heat-cure acrylic resins.

\section{MATERIALS AND METHODS}

\section{Materials}

The two heat-cure denture base resin materials and household denture cleansers chosen for the study are given in Table 1. A total of 48 Trevalon and Lucitone 199 heat-cure resin samples respectively were fabricated. A metal die of dimension $65 \times 10 \times 2.5 \mathrm{~mm}$ in length, width
Table 1: Materials used for sample preparation

\begin{tabular}{ll}
\hline Brand name & Manufacturer \\
\hline Trevalon & Dentsply India Pvt Ltd. \\
Lucitone 199 & Dentsply International Inc. \\
& York, PA 17405-0872 \\
White distilled vinegar & American Garden Products \\
Superior bleaching powder & Standard Chemical Industries \\
\hline
\end{tabular}

Abbreviations used in forthcoming tables: Group I: Trevalon heat cure samples; Group II: Lucitone 199 heat cure samples; Subgroup A1: Trevalon samples immersed in $1 \%$ household bleach; Subgroup B1: Trevalon samples immersed in 50\% Vinegar; Subgroup C1: Trevalon samples immersed in water (control); Subgroup A2: Lucitone 199 samples immersed in 1\% household bleach; Subgroup B2: Lucitone 199 samples immersed in 50\% Vinegar; Subgroup C2: Lucitone 199 samples immersed in water (control)

and thickness respectively was used for fabrication of the two heat-cure resin samples. Both, the resins were mixed and processed according to the manufacturers instructions.

\section{Methods}

The samples were divided into three groups of 16 samples each. In the first group labeled as group A samples were immersed in household bleach (sodium hypochlorite). One percent solution of bleach was used for the study. ${ }^{8,9,11}$ In the second group labeled as group B samples were immersed in vinegar (acetic acid). Fifty percent solution of vinegar was used for the study. ${ }^{12}$ In the third group labeled as group C samples were immersed in water which was used as the control group. The samples were alternatively immersed in cleanser and water for 8 hours for 20 days simulating 30 days of use of cleanser. At the end of 20 days color stability and tensile strength were assessed with the help of spectro-guide and Instron universal testing machine respectively.

Spectro-guide is a portable spectrophotometer. The color difference was evaluated using Commission Internationale de I 'Eclairage' (CIE) L*a*b* colorimetric system. This system is based on three parameters defining color: $L^{*}$ represents lightness, $a^{*}$ represents red green and $\mathrm{B}^{*}$ represents yellow-blue. The total color difference is expressed by the formula

$\Delta \mathrm{E}=\left(\Delta \mathrm{L}^{2}+\Delta \mathrm{a}^{2}+\Delta \mathrm{b}^{2}\right)$

$\Delta \mathrm{E}^{*}=$ color difference

$\Delta \mathrm{L}^{*}=$ changes in $\mathrm{L}^{*}$ between the interval of interest and baseline

$\Delta \mathrm{a}^{*}=$ changes in $\mathrm{a}^{*}$ between the interval of interest and baseline

$\Delta \mathrm{b}^{*}=$ changes in $\mathrm{b}^{*}$ between the interval of interest and baseline

To measure tensile strength on Instron machine, sample was strained uniformly along its length. The 
machine was started at a steady rate at a crosshead speed of $10 \mathrm{~mm} / \mathrm{min}$. The tensile strength was calculated using the formula:

Tensile strength $=$ force $(\mathrm{n}) / \operatorname{area}\left(\mathrm{mm}^{2}\right)$

\section{Data Analysis}

The obtained results were then analyzed statistically using student's t-test, 2-way analysis of variance (ANOVA) and Newman-Keuls multiple post hoc procedure.

\section{RESULTS}

The mean and standard deviation of color change ( $\Delta \mathrm{E}$ values) of Trevalon (group I) and Lucitone 199 (group II) heat-cure resins are given in Table 2. It was seen that there was significant difference in color between

Table 2: Comparison of groups I and II with respect to color stability ( $\Delta \mathrm{E}$ values) by student's t-test

\begin{tabular}{lllll}
\hline Groups & Mean & Standard deviation & $t$-value & $p$-value \\
\hline I & 60.1583 & 1.3212 & -4.2550 & $0.0001^{*}$ \\
II & 61.6981 & 1.1823 & & \\
\hline${ }^{*} p<0.05$ & & &
\end{tabular}

both the groups when analyzed using student's t-test ( $\mathrm{p}=0.0001^{*}$ significant at $5 \%$ level of significance). Analysis using 2-way ANOVA also showed significant difference in color between both the acrylic resins ( $p=0.0000^{*}$ significant at $5 \%$ level of significance) and between the cleansers ( $p=0.0001^{*}$ significant at $5 \%$ level of significance) as seen in Table 3. Table 4 displays the interaction between all the sub groups of Trevalon and Lucitone 199 samples analyzed using Newman-Keuls multiple post hoc procedure. It was seen that significant color change was present in Lucitone 199 samples immersed in bleach and vinegar when compared with water $\left(p=0.0004^{*}\right.$ and $p=0.0003^{*}$ respectively significant at $5 \%$ level of significance).

The mean and standard deviation values for tensile strength are presented in Table 5. It was seen that there was no significant difference in tensile strength between both the groups when compared by student's t-test. On comparing the two groups and subgroups with each other and among themselves using 2-way ANOVA, it was seen that there was no significant change in tensile strength as displayed in Table 6.

Table 3: Comparison of two groups and three subgroups with respect to color stability ( $\Delta \mathrm{E}$ values) by 2-way ANOVA

\begin{tabular}{llllll}
\hline Source variation & Degree of freedom & Sum of squares & $\begin{array}{l}\text { Means of sum of } \\
\text { squares }\end{array}$ & $\begin{array}{l}\text { Snedecors ' } F \text { ' } \\
(f \text {-value })\end{array}$ & Probability ( $p$-value) \\
\hline Main effects & 1 & 28.4548 & 28.4548 & 32.8599 & $0.0000^{*}$ \\
Groups & 2 & 19.2795 & 9.6398 & 11.1321 & 0.0001 \\
Subgroups & & & & \\
2-way interactions & & 16.6480 & 8.3240 & 9.6127 & $0.0004^{*}$ \\
Groups $\times$ subgroups & 2 & 36.3696 & 0.8659 & & \\
Error & 42 & 100.7520 & & & \\
\hline Total & 47 & & &
\end{tabular}

${ }^{*} p<0.05$

Table 4: Comparison of interaction of main groups and subgroups $(A B C)$ with respect to color stability $(\triangle E$ values) by NewmanKeuls multiple post hoc procedure

\begin{tabular}{|c|c|c|c|c|c|c|}
\hline Interaction & $\begin{array}{l}\text { Group I × } \\
\text { subgroup A }\end{array}$ & $\begin{array}{l}\text { Group I } \times \\
\text { subgroup B }\end{array}$ & $\begin{array}{l}\text { Group I } \times \\
\text { subgroup C }\end{array}$ & $\begin{array}{l}\text { Group II } \times \\
\text { subgroup } A\end{array}$ & $\begin{array}{l}\text { Group II } \times \\
\text { subgroup B }\end{array}$ & $\begin{array}{l}\text { Group II } \times \\
\text { subgroup C }\end{array}$ \\
\hline Mean & 61.07896 & 59.41167 & 59.98414 & 62.28437 & 62.53198 & 60.27807 \\
\hline Group I × Subgroup A & - & - & - & - & - & - \\
\hline Group I × Subgroup B & $0.0048^{*}$ & - & - & - & - & - \\
\hline Group I × Subgroup C & 0.0595 & 0.2255 & - & - & - & - \\
\hline Group II × Subgroup A & $0.0132^{*}$ & $0.0001^{*}$ & $0.0002^{*}$ & - & - & - \\
\hline Group II × Subgroup B & $0.009^{*}$ & $0.0001^{*}$ & $0.0002^{*}$ & 0.5975 & - & - \\
\hline Group II $\times$ Subgroup C & 0.0927 & 0.1625 & 0.5311 & $0.0004^{*}$ & $0.0003^{*}$ & - \\
\hline
\end{tabular}

${ }^{*} p<0.05$

Table 5: Comparison of groups I and II with respect to tensile strength by student's t-test

\begin{tabular}{lllll}
\hline Groups & Mean & Standard deviation & $t$-value & $p$-value \\
\hline I & 36.1675 & 4.2957 & -1.4685 & 0.1488 \\
II & 38.0846 & 4.7380 & & \\
\hline
\end{tabular}


Table 6: Comparison between two groups and three subgroups with respect to tensile strength using 2-way ANOVA

\begin{tabular}{llllll}
\hline Source variation & Degree of freedom & Sum of squares & $\begin{array}{l}\text { Means of sum of } \\
\text { squares }\end{array}$ & $\begin{array}{l}\text { Snedecors ' } F \text { ' } \\
(f \text {-value })\end{array}$ & $\begin{array}{l}\text { Probability } \\
(p \text {-value })^{*}\end{array}$ \\
\hline $\begin{array}{l}\text { Main effects } \\
\text { Groups }\end{array}$ & 1 & 44.1025 & 44.1025 & 2.0828 & 0.1564 \\
Subgroups & 2 & 2.0641 & 1.0320 & 0.0487 & 0.9525 \\
2-way interactions & & & & & \\
Groups $\times$ subgroups & 2 & 49.3499 & 24.6750 & 1.1653 & 0.3217 \\
Error & 42 & 889.3158 & 21.1742 & & \\
\hline Total & 47 & 984.8324 & & & \\
\hline
\end{tabular}

${ }^{*} p<0.05$

\section{DISCUSSION}

One of the factors affecting longevity of denture is denture hygiene. Poor denture hygiene results in accumulation of debris and plaque on denture. This further leads to inoculation of microorganisms, most commonly C. albicans which might lead to denture stomatitis. It is futile to eliminate microorganisms from mouth if the oral tissue is inoculated repeatedly by a contaminated denture. ${ }^{13}$ This is also important in patients who are chronically ill or debilitated or have undergone oral surgical procedures. It has been reported that dentures also get contaminated while polishing in the laboratory. ${ }^{5}$ It is important to disinfect the dentures with cleansers before inserting them in the patient.

Denture cleansers used for maintaining denture hygiene should not affect the physical properties of acrylic resins. Brushing is one of the most commonly used effective mechanical method for cleaning dentures. But incorrect technique of brushing results in abrasion of denture. The resulting rough surface acts as a rich substrate for colonization of bacteria and further staining of denture. It has been shown that brushing alone is not sufficient for good denture biofilm control, and hence chemical cleansers have to be used as an adjunctive measure to mechanical cleanser to complement denture hygiene. ${ }^{6}$

These cleansers should not only remove stains and debris from denture but they should also be effective disinfecting agents. Chemical denture cleansers can be broadly divided into two groups: commercial and household cleansers. Those household products which are used for cleaning denture cleansers can be classified as household denture cleansers.

Chemical denture cleansers depending upon its content can be divided into five groups: alkaline hypochlorite, alkaline peroxide, dilute organic and inorganic acid, disinfectant and enzymes. ${ }^{13}$ Most of the commercially available cleansers in India have alkaline peroxide as their main constituent.

Geriatric population constitutes majority of the denture wearers. ${ }^{14}$ In India, most of the complete denture wearers belong to the lower socioeconomic strata of the society. They are unable to afford commercial denture cleansers. Some of the denture wearing population is ignorant of commercial denture cleansers. Due to advanced age regularly commuting to shop becomes difficult to buy denture cleansers. Also, the denture cleansers are not available in all pharmaceutical shops in India especially in remote areas. In all such cases, patients prefer using household cleansers which are easily available on shelf in the house.

Household bleach and vinegar are two such products which are used as denture cleansers. Household bleach is chemically sodium hypochlorite. It is used to remove stains and disinfect surfaces. Sodium hypochlorite is relatively inexpensive and presents a broad spectrum of activity. In dentistry, bleach is used as a disinfectant and denture cleansers. Lima et al found that amount of biofilm formed on acrylic resin specimens treated with sodium hypochlorite was statistically less. They are effective for plaque dissolution due to the alkaline $\mathrm{pH}$ and may inhibit calculus formation because of their effect on plaque matrix. ${ }^{15}$ Full strength sodium hypochlorite has been shown to be effective against microorganisms including spores. ${ }^{5}$ Anthony and Gibbons suggested a combination of sodium hypochlorite and water to remove heavier deposits and stains. They found household cleansers to be more effective than commercial denture cleansers in removal of deposits and stains. ${ }^{13}$

Vinegar is not frequently used as a disinfectant in dentistry. In literature of other areas, it is cited as a promising alternative disinfectant particularly due to its low toxicity. It has been shown to be as effective as $1 \%$ sodium hypochlorite and $2 \%$ glutaraldehyde in disinfection. ${ }^{8}$

Ideally, after the use of disinfectants and cleansers the physical and mechanical properties of denture base resins should remain unaltered. But, it has been seen that daily use of denture cleansers affects physical properties of denture base resins. It has been demonstrated that alcohol based, phenolic based and hypochlorite based denture cleansers affect the hardness, flexural strength and color stability of denture base resins. These changes have been attributed to a structural change in polymer 
interstitial matrix. The degree of influence depends upon the duration of immersion and type of cleanser used. ${ }^{11}$

Color stability is one of the important properties of denture base resins. Color change is an indicator of aging/damage to acrylic resin. It gives information on serviceability of material. ${ }^{16}$ Some denture cleansers have harmful effects on resin and may adversely affect its color and surface luster. Discoloration may take place because of leaching of low molecular weight components. Stains on the denture and discoloration of denture base resins lead to unesthetic appearance.

There are contradictory findings on effect of sodium hypochlorite on acrylic resins. Kazanji, Ahmad and Ma T et al reported that sodium hypochlorite alters color of acrylic resin. ${ }^{7,10}$ But, Rudd et al, Polyzois et al, and Mc Neme et al found that sodium hypochlorite did not affect the color of resin. If the color change was present it was not statistically significant. 5,9,17 According to Kazanji and Ahmad, vinegar did not affect the color of resin significantly. ${ }^{10}$

In the present study, on immersing samples of both Trevalon and Lucitone 199 in bleach and vinegar, it was seen that statistically significant change was present in color in samples of Lucitone 199 when compared with the control group. But, the color change in Trevalon samples was statistically insignificant. Sarac et al and Purnaveja et al reported that denture cleansers can cause whitening or bleaching, loss of soluble components or water absorption in acrylic resin materials. Acrylic resin tends to change color on immersion in distilled water for long period of time. ${ }^{16}$ This could be as a result of leaching out of coloring agents.

According to Kazanji and Ahmad, sodium hypochlorite produced a significant decrease in optical density of heat cured resin; this indicated that the concentration of colored substance was reduced. They also reported that vinegar did not change the color of acrylic resin. The agents which change color by decreasing the optical density are more harmful than those which increase the optical density since the original concentration of colored substance is decreased. ${ }^{10}$

Reports have shown that color change in denture base material is caused by changes in matrix of material, staining effect of external colorants, solubility, water sorption, leakage, surface roughness and chemical degradation. ${ }^{16}$ As seen in the present study though sodium hypochlorite and vinegar affected color of Lucitone 199 samples, the color of Trevalon samples remained unchanged. This could be because of the difference in polymerization and particle size of both the resins. From all the above findings it can be concluded that change in color of resin after immersion in any cleanser cannot be attributed only to the cleanser. Water which is used for diluting the cleansers itself changes color over a period of time. The effect of cleanser on color of denture base resin depends on the properties of the denture base resin as well.

da Silva et al and Pavarina et al found out that chlorhexidine gluconate and sodium hypochlorite affected the surface roughness of acrylic resin. Vinegar did not affect the surface roughness of acrylic resin. ${ }^{8}$ According to Neppelenbroek et al 1\% sodium hypochlorite decreased the hardness of acrylic resin. They speculated that sodium hypochlorite may have penetrated into acrylic resin causing its softening. But, there was no statistically significant difference in hardness in test group and control group samples. ${ }^{11}$ Asad et al reported that on immersing Trevalon heat-cure acrylic and homopolymer acrylic resin samples in alcohol, glutaraldehyde and chlorhexidine, flexural strength of Trevalon acrylic resin remained unaffected while that of homopolymer decreased. They attributed this to the alcohol which acted as a solvent causing crazing on surface of homopolymer acrylic resin making it more prone to fracture. Trevalon being cross linked polymer remained unaffected by the disinfectants. ${ }^{18}$

In the present study, tensile strength of both the samples was not significantly affected on comparing the test groups with control group. The two resins, Trevalon and Lucitone 199 are cross linked polymers. This might me the probable reason due to which the tensile strength unchanged.

Though bleach (sodium hypochlorite) and vinegar (acetic acid) affected the color stability of Lucitone 199, whether the change was clinical visible was not evaluated. This is important since only if the color change is visible to naked eye will it be of clinical relevance.

\section{CONCLUSION}

The present study concludes that sodium hypochlorite and vinegar affected the color stability of Lucitone 199 heat-cure acrylic resin. The color of Trevalon heat-cure resin remained unaltered after immersion in both the cleansers. The change in tensile strength of both the resins was not statistically significant after immersion in both the cleansers as compared with water which was used as control group.

For disinfection and cleansing of dentures, sodium hypochlorite can be considered as long as the acrylic is cross linked. The effect of cleansers on properties of acrylic resins differs with the resins used as well as the cleansers. Water which is used for diluting the cleansers itself changes color of resin over a period of time. Hence, change in color of resin after immersion in any cleanser cannot be attributed only to the cleanser. 


\section{REFERENCES}

1. Hong G, Murata H, Li Y, Sadamori S, Hamada T. Color stability of three types of denture base acrylic resin. J Prosthet Dent 2009 Mar;101(3):205-213.

2. Nikawa H, Hamada T, Yamamoto T, Kumagai H. Effects of salivary or serum pellicles on the Candida albicans growth and biofilm formation on soft lining materials in vitro. J Oral Rehabil 1997 Aug;24(8):594-604.

3. Nikawa $\mathrm{H}$, Hamada $\mathrm{T}$, Yamashiro $\mathrm{H}$, Kumagai $\mathrm{H}$. A review of in vitro and in vivo methods to evaluate the efficacy of denture cleansers. Int J Prosthodont 1999 Mar-Apr;12(2):153-159.

4. Nikawa $H$, Iwanaga $H$, Hamada $T$, Yuhta S. Effects of denture cleansers on direct soft denture lining materials. J Prosthet Dent 1994 Dec;72(6):657-662.

5. Rudd RW, Senia ES, McCleskey FK, Adams ED. Sterilization of complete dentures with sodium hypochlorite. J Prosthet Dent 1984;51(3):318-321.

6. Sato S, Cavalcante MRS, Orsi IA, Paranhos HFO, Zanquelli O. Assessment of flexural strength and colour alteration of heat polymerised acrylic resin after simulated use of denture cleansers. Braz Dent J 2005;16(2):1-8.

7. Ma T, Johnson GH, Gordon GE. Effects of chemical disinfectants on the surface characteristics and colour of denture resins. J Prosthet Dent 1997;77(2):197-204.

8. Silva FC, Kimpara ET, Mancini MNG, Balducci I, Jorge AOC, Koga-Ito CY. Effectiveness of six different disinfectants on removing five microbial species and effects on the topographic characteristics of acrylic resin. J Prosthodont 2008;17(8): 627-633.
9. Mc Neme SJ, Gonten AS, Woolsey GD. Effects of laboratory disinfecting agents on colour stability of denture acrylic resins. J Prosthet Dent 1991;66(1):132-136.

10. Kazanji MN, Ahmad ZM. Evaluation of the effect of some denture cleansers on the colour of acrylic resin denture base materials. Al-Rafidain Dent J 2004;4:79-86.

11. Neppelenbroek KH, Pavarina AC, Vergani CE, Giampaolo ET. Hardness of heat polymerised acrylic resin after disinfection and long term water immersion. J Prosthet Dent 2005;93(2): 171-176.

12. Basson NJ, Quick AN, Thomas CJ. Household products as sanitizing agents in denture cleaning. J Dent Assoc S Afr 1992;47(10):437-439.

13. Moore TC, Smith DE, Kenny GE. Sanitization of dentures by several denture hygiene methods. J Prosthet Dent 1984;52(2): 158-163.

14. Shay K. Denture hygiene: a review and update. J Contemp Dent Pract 2000 Feb 15;1(2):28-41.

15. Lima EMCX, Moura AA, Cury DB, Garcia RCMR, Cury JA. Effect of enzymatic and $\mathrm{NaOCl}$ treatments on acrylic roughness and on biofilm accumulation. J Oral Rehabil 2006; 33(5):356-362.

16. Hong G, Murata H, Li Y, Sadamori S, Hamada T. Influence of denture cleansers on the colour stability of three types of denture base acrylic resins. J Prosthet Dent 2009;101(3):205-213.

17. Polyzois GL, Yannikakis SA, Zissis AJ, Demetriou PP. Colour changes of denture base materials after disinfection and sterilization immersion. Int J Prosthodont 1997;10(1):83-89.

18. Asad T, Watkinson AC, Hugget R. The effect of disinfection procedures on flexural properties of denture base acrylic resins. J Prosthet Dent 1992;68(1):191-195. 